Journal of Engineering and Applied Sciences 5 (1): 36-44, 2010

ISSN: 1816-949X

(C) Medwell Journals, 2010

\title{
Taguchi Based Linear Regression Modeling of Flat Plate Heat Sink
}

\author{
${ }^{1} \mathrm{~S}$. Manivannan, ${ }^{2}$ R. Arumugam, ${ }^{3}$ N.M. Sudharsan and ${ }^{4}$ S. Prasanna Devi \\ ${ }^{1}$ Department of Electrical and Electronics Engineering, Anna University, India \\ ${ }^{2}$ Department of Electrical and Electronics Engineering, SSN College of Engineering, India \\ ${ }^{3}$ Sarvajit-CAE, Chennai, India \\ ${ }^{4}$ Department of Industrial Engineering, Anna University, India
}

\begin{abstract}
This study presents an approach for the multiple linear regressions modeling of the flat plate heat sink using Taguchi Design of Experiments method. The responses studied were electromagnetic radiation and thermal resistance of the heat sink. The heat sink is modeled using Ansoft HFSS and Flotherm software for finding the emitted radiation and thermal resistance of the heat sink respectively. Experimental investigations were performed to find the thermal resistance and emitted radiations from the heat sink and thus the simulation model was validated with the experimental results. The simulations were continued for the combinations generated by the L27 ( 6 factors, 3 levels) Taguchi's Design of Experiments using Minitab software. The factors considered for L 27 are the length and width of the heat sink, Fin height, Base height, Number of fins and fin thickness. The values of responses are used to develop Meta models for the heat sink using multiple linear regression analysis. Thus the developed meta models replaces the use of the above mentioned simulation software's for finding out the responses by saving the modeling, simulation time and cost of simulation software
\end{abstract}

Key words: Heat sink, Taguchi Design of Experiments (DOE), HFSS simulation, CFD simulation, experimentation, multiple linear regression analysis

\section{INTRODUCTION}

The heat sinks are used in electronic systems to remove heat from the chip and effectively transfer it to the ambient (Rao, 2001). The heat sink geometry is designed by the mechanical engineers with the primary aim of reducing the thermal resistance of the heat sink for better cooling in the electronic systems. Due to the proximity of the heat sink with the ICs, the RF fields created by RF currents in the ICs/PCBs gets coupled to heat sinks. The fin of the heat sink effectively behaves as monopoles at high frequency. Hence, the coupled RF current can cause radiated emission. This radiated noise from the device can couple and disturb the functioning of the nearby electronic systems.

Also this radiated emission from the device poses a problem to the system compliance with respect to EMI/EMC regulations. The international EMI/EMC standards require the radiated emission from the electronic devices to be kept below the specified limits. Various techniques are practiced by the EMC engineers to suppress the radiated emission but reducing the emission from the source point is the most preferred. Hence EMC engineers need to understand the factors contributing to radiated emission from heat sink. It is important to analyze and optimize these factors, mainly the geometrical parameters of heat sink to minimize the radiated emissions at the design stage itself. Das and Roy (1998) observed that the radiating efficiency not only depends on the clock frequency of the ASIC but also on the shape of the heat sink.

The radiated emissions are most severe when the monopole length becomes quarter of the wavelength and vertical polarized emissions were found to be higher than the horizontal polarization and the highest emission was observed when vertical length of the heat sink became sixth or fifth of the wavelength and concluded that circular heat sink can be modeled as a monopole.

Brench (1994) examined the variations in the radiation characteristics of heat sink with respect to their geometries by applying 3D-FDTD technique and found that there is an additional increase in radiated emissions at the resonance of the heat sink.

Corresponding Author: S. Manivannan, Department of Electrical and Electronics Engineering, Anna University, India 
Parry (2000) presented approach for modeling heat sink and studied the effect of grounded heat sink and examined the common mode RF coupling between die and heat sink and concluded that heat sink radiating clock harmonics throughout the frequency spectrum. Golkhab and Bina (2008) studied the effect of reduction in space for the want of compactness in geometry and specified effect of more EMI problems when the components become much closer.

Georgerian and Mantrose (2003) studied the concept of wavelength based heat sink fin length selection for the minimization of radiated emissions and simultaneously they presented an approach for the base temperature rise with the variation in fin length for maximizing cooling the cooling of electronic packages.

Archambeault et al. (2001) discussed the effects of EMI by heat sink and presented a method to suppress its effects by grounding techniques. Lu and Duan (2007) presented a approach of applying finite element frequency domain analysis for electromagnetic radiation emitted from high power microelectronic circuits connected to heat sink and also investigated various grounding options of the heat sink.

Lu and Dawson (2006) studied the EMC computer modeling techniques for CPU heat sink simulation and presented an approach to model and simulate a heat sink also found a resonant frequency of $2.6 \mathrm{GHz}$ with a reflection coefficient of $-8.3 \mathrm{~dB}$ for Intel CPU heat sink, which is closer to IEEE and Bluetooth wireless communication systems and concluded that heat sink behaves like an efficient radiator for these range of frequencies.

Yu et al. (2008) modeled heat sink using Micro stripes (Flomerics) to find radiations emitted from the heat sink also found the variation in radiation for the variation in design factors like height and number of fins and concluded that there is a considerable variation in radiation for the variations in the total number of fins but the influence of other design parameters like length and width of heat sink, fin thickness and base height are not studied.

Visser et al. (2000) described the use of mathematical optimization techniques to minimize the heatsink mass or thermal resistance using five design variables namely, heatsink height, thickness, extrusion length, base thickness and number of fins for the heatsink. The study shows how the parameters considered influence the heatsink mass and how mathematical optimization techniques can be used by the heatsink designer to design compact heatsinks for different types of electronic enclosure. Culham and Muzychka (2001) presented a procedure for optimization of heatsink design parameters based on minimization of the entropy generation associated with heat transfer and fluid friction. In addition, a novel approach for incorporating forced convection through the specification of a fan curve is integrated into the optimization procedure providing a link between optimized design parameters and the system operating point. Shah et al. (2002) examined the effect of the shape of the heatsink fins particularly near the center of the heatsink. An optimum heatsink shape is reported that results in a lower operating temperature and pressure gradient. Khan et al. (2006) studied the Entropy Generation Minimization (EGM) procedure is employed to optimize the overall performance of micro channel heatsinks using Newton-Raphson method.

Bar-Cohen and Rohsenow (1984) analyzed the thermally optimum spacing of vertical natural convection cooled parallel palates. Bar-Cohen (1992) and Kraus and Bar-Cohen (1995) has analyzed the state of art and trends in thermal packing of electronic packages and detailed analysis on the design of heatsinks. Chen et al. (2008) has done the parameter optimization of plate fin heat sink (with side cooling fan) using genetic algorithm and developed a direct adaptive control scheme for the CPU heat sink process using a bounded single neuron controller to regulate the temperature of a selected control point.

Lin has studied the use of the Taguchi method and GRA to optimize turning operations with multiple performance characteristics. Ching has studied the optimum design parameters of pin-fin heat sink using the grey-fuzzy logic based on the orthogonal arrays. The effects of design parameters and the optimum design parameters for a Pin-Fin Heat Sink (PFHS) with the multiple thermal performance characteristics have been investigated by using the grey-fuzzy logic based on the orthogonal arrays. Various design parameters, such as height and diameter of pin-fin and width of pitch between fins were considered. Chou et al. (2009) studied the optimization of a Parallel-Plain Fin (PPF) heat sink using the grey-based fuzzy algorithm with the orthogonal arrays. The study done by Arularasan and Velraj (2008) presents the modeling and simulation of parallel plate heat sinks using CFD and DOE considers the factors like number of fins $(\mathrm{N})$, fin length $(\mathrm{L})$, fin height (a), base height (b) of the heat sink to optimize the thermal resistance of the heat sink.

In the present study, the researchers focus in developing a meta model for the heat sink performance 
factors like emitted radiation and thermal resistance found from the geometry factors such as length (L), width (W) of the heat sink, height of the fin (a), base height of the heat sink (b), number of fins $(N)$ and fin thickness (d) of a flat plate heat sink. In this study, the Taguchi design of experiments is used to generate the various geometry combinations of the heat sink and the various performance characteristics for each combination were found using HFSS and Flotherm simulations. The developed meta models replaces the use of the simulation software's (Flotherm and Ansoft) for finding out the responses, thus by saving the modeling and simulation time and cost.

\section{MATERIALS AND METHODS}

2 HFSS modeling, simulation and experimentation of heat sink for finding radiated emissions: A typical aluminum heat sink with the geometry specifications available in Table 1 is modeled using Ansoft HFSS version 12. The model essentially consists of three regions namely the heat sink region, source region and the ground plane. The aluminum ground plane is modeled with the dimensions $150 \times 1356 \times 1 \mathrm{~mm}$ below the heat sink at a distance of $5 \mathrm{~mm}$. The typical flat plate heat sink with ' $N$ ' number of fins is shown in Fig. 1.

Lumped port of impedance $50 \Omega$ is defined to represent the coupling of processor to the heat sink. Also, there is no any additional grounding point for this processor to suppress the radiations to avoid additional cost and space restrictions. The radiation boundary is defined to specify an open boundary condition that

Table 1: Heat sink geometry used for simulation

\begin{tabular}{llllll}
$\begin{array}{l}\text { Length of } \\
\text { the heat } \\
\text { sink, }\end{array}$ & $\begin{array}{l}\text { Width of } \\
\text { the heat } \\
\text { sink, }\end{array}$ & $\begin{array}{l}\text { Fin } \\
\text { height, }\end{array}$ & $\begin{array}{l}\text { Base } \\
\text { height, }\end{array}$ & $\begin{array}{l}\text { Number } \\
\text { of fins, }\end{array}$ & $\begin{array}{l}\text { Fin } \\
\text { thickness, }\end{array}$ \\
\hline $\mathrm{L}(\mathrm{mm})$ & W $(\mathrm{mm})$ & $\mathrm{a}(\mathrm{mm})$ & $\mathrm{b}(\mathrm{mm})$ & $\mathrm{N}$ & $\mathrm{d}(\mathrm{mm})$ \\
\hline 90 & 70 & 30 & 6 & 17 & 1.2 \\
\hline
\end{tabular}

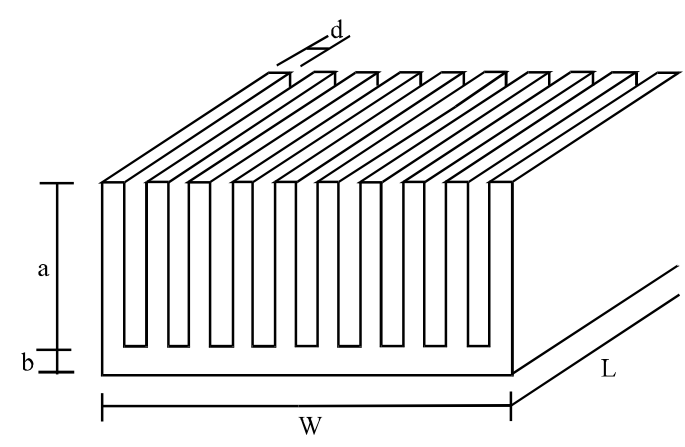

Fig. 1: Typical flat plate heat sink model allows waves to radiate infinitely into space. The radiation boundary in the present problem is defined as box with faces positioned at least a quarter wave length $(\lambda / 4)$ from the objects in the model.

The total emissions from the heat sink are evaluated in the far field region by defining an infinite sphere that surrounds the radiating object. The source power level to excite heat sink is kept at $1 \mathrm{~mW}$. The simulation was carried for the frequencies ranging from (1-10) G Hz with an interval of $500 \mathrm{MHz}$. The emissions are obtained in terms of $(\mathrm{dBmV} / \mathrm{m})$ at a distance of $3 \mathrm{~m}$ from the source. The 3D far field radiation pattern for the $\mathrm{E}$ field at $3 \mathrm{GHz}$ of the heat sink and the boundary are shown in the Fig. 2 . The same aluminum heat sink with the specifications given in Table 1 is used for the experimental investigation.

An aluminum ground plane of dimensions $150 \mathrm{~mm} \mathrm{X}$ $135 \mathrm{~mm} \mathrm{X} 1 \mathrm{~mm}$ is placed at $5 \mathrm{~mm}$ below the heat sink with a N-Type male connector fixed at the center for the excitation. The center pin of the N-Type connector is extended and soldered to the base of the heat sink with a copper wire. The radiation from a heat sink is experimentally measured in a shielded semi-anechoic chamber. The set-up for the experimental analysis is shown in Fig. 3. The test setup consist of the components such as Log periodic antenna, Signal generator, Turn table, Insulation material, Heat sink and ground plane and Spectrum analyzer.

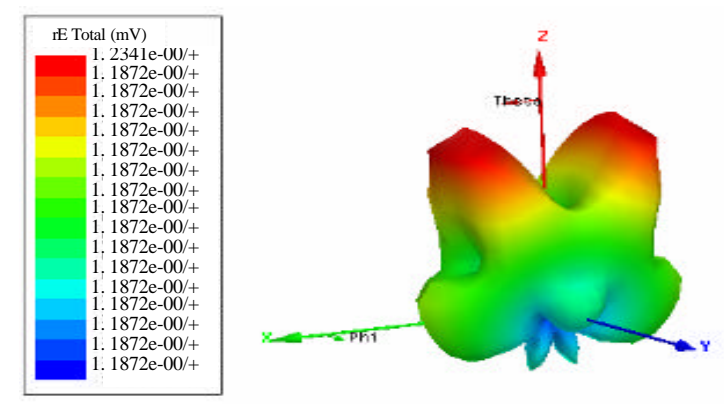

Fig. 2: Far field radiation pattern of heat sink

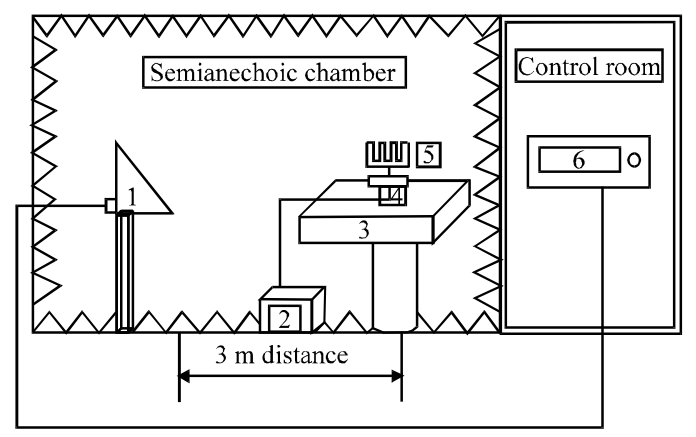

Fig. 3: Schematic diagram of experimental setup 


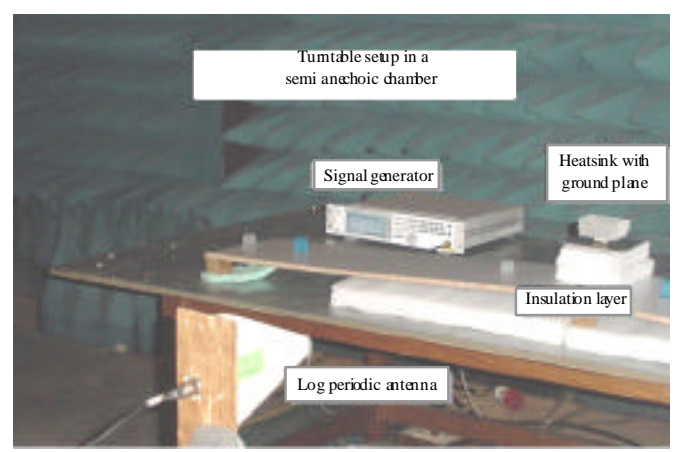

Fig. 4: Photograph of experimental setup

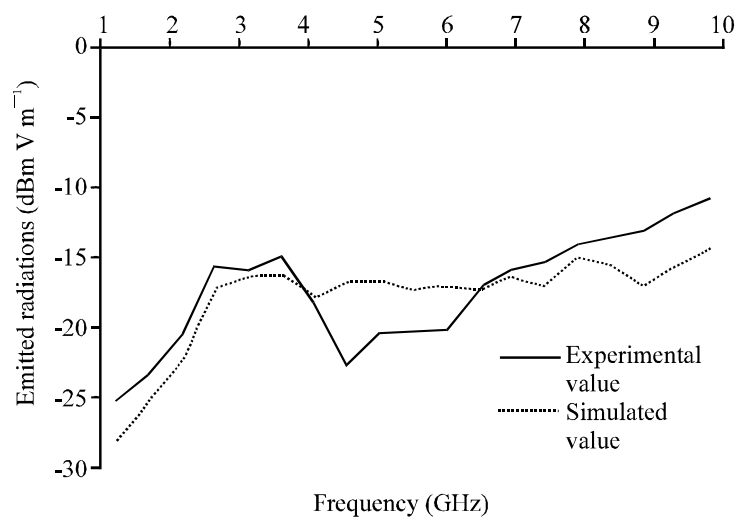

Fig. 5: Comparison of simulation vs experimental results

The heat sink is excited using the Agilent-MXGanalog signal generator and swept for the range of frequencies between 1-10 GHz with a RF output of 1 milliwatt $(0 \mathrm{dBm})$ at $50 \Omega$ impedance. RF SMA Cable was used to connect the signal generator to the $\mathrm{N}$ connector of the base plate via SMA-N adaptor. A log periodic antenna of SAS make-200/518 was placed at a distance of $3 \mathrm{~m}$ from the heat sink to receive the radiations emitted. The antenna is vertically polarized and connected to Agilent spectrum analyzer which is kept in the control room via N-Type RF cable. Figure 4 shows the photograph of the experimental setup. Signal generator is set to provide RF signal with a range of $1-10 \mathrm{GHz}$ with a step size of $500 \mathrm{MHz}$. The radiated emissions from the heat sink are measured using spectrum analyzer. The radiated emission from the heat sink obtained via experimentation and simulation were plotted with Frequency $(\mathrm{GHz})$ and emitted radiation $(\mathrm{dBmV} / \mathrm{m})$ along $\mathrm{X}$ and $Y$, respectively and is shown in Fig. 5.

3 CFD modeling, simulation and experimentation of heat sink for finding thermal resistance of heat sink: The thermal performance characteristics of a heat sink such as

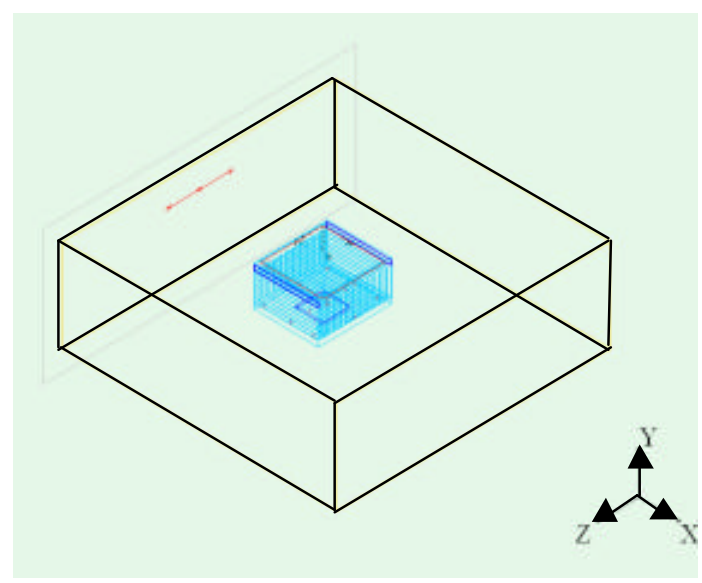

Fig. 6: CFD modeling of heatsink using flotherm

Table 2: Inlet boundary conditions and material properties

\begin{tabular}{ll}
\hline Parameters & Value \\
\hline Ambient temperature & $301 \mathrm{k}$ \\
Thermal conductivity of extruded & $209 \mathrm{~W} \mathrm{mk}^{-1}$ \\
aluminum heatsink & \\
Density of extruded aluminum & $2684.9 \mathrm{~kg} \mathrm{~m}^{-3}$ \\
Conductivity of air & $0.026274 \mathrm{~W} \mathrm{mk}^{-1}$ \\
Viscosity of air & $0.00001824 \mathrm{~kg} \mathrm{~ms}^{-1}$ \\
Density of air & $1.1758 \mathrm{~kg} \mathrm{~m}^{-3}$ \\
Specific heat capacity of air & $1005.49967 \mathrm{Ws} \mathrm{kg}^{-1} \mathrm{k}$ \\
\hline
\end{tabular}

the thermal resistance is found using CFD simulations. A numerical model was formulated using commercial CFD package Flotherm Version 7.2 [26] for solving three dimensional heat transfers in the heat sink with a fan of $70 \mathrm{~mm}$ opening is shown in Fig. 6.

The heat sink with specifications in Table 1 is modeled using Flotherm. A heat source of size $3 \times 3 \mathrm{~cm}$ is modeled and attached to the bottom of heatsink and a layer of Wakefield thermal compound with a thermal resistivity of $0.735 \mathrm{~W} \mathrm{mK}^{-1}$ is applied between heat sink and heat source to provide a proper surface contact between them. The inlet boundary conditions and material properties are given to Flotherm software as inputs are given in Table 2.

The program is set to run for 500 iterations. The base temperature of the heat sink is measured at various six points at heat sink base. The heater load is varied from $10-80 \mathrm{~W}$ at an interval of $10 \mathrm{~W}$. For each heat loads, the base temperatures are recorded and average base temperature is found. The corresponding thermal resistance values are obtained using Eq. 1.

$$
\mathrm{R}_{\sin }=\frac{\Delta \mathrm{T}}{\mathrm{Q}}
$$

Where:

$$
\Delta \mathrm{T}=\mathrm{T}_{\mathrm{b}}-\mathrm{T}_{\mathrm{a}}
$$




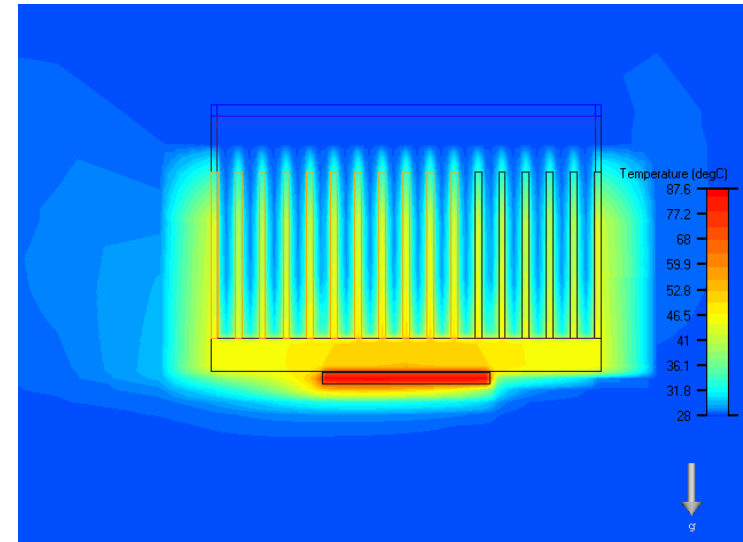

Fig. 7: Temperature distribution plot of original heat sink

Figure 7 shows the temperature distribution plot of the CFD simulation using Flotherm software with a heat load of $80 \mathrm{~W}$. From the average values of base temperature, the simulated value of thermal resistance of a heat sink is found as $0.2368^{\circ} \mathrm{K} \mathrm{W}^{-1}$.

Full scale experimentation is performed for the heat sink with geometry specified in Table 1 by mimicking the Watt density, i.e. the heat dissipated by various processors from $10-80 \mathrm{~W}$. An experimental setup is arranged with an electric heater of size $30 \times 30 \mathrm{~mm}$ as a heat source to mimic a processor and it is supplied by DC power supply. The heater is fixed with heat sink using Anabond compound with thermal conductivity of $0.437 \mathrm{~W} \mathrm{mK}^{-1}$ and Wakefield thermal compound with thermal conductivity of $0.735 \mathrm{~W} \mathrm{mK}^{-1}$ is applied to the contact surface of the sink to make proper surface contact between heatsink and the heater. The heatsink rejects the heat into the air which is enhanced by placing the axial fan above the heatsink.

The axial fan with a opening of $70 \mathrm{~mm}$ diameter is placed on the top the heat sink and the fan is charged by $12 \mathrm{~V} \mathrm{D}$.C supply. The bottom side of the heater is insulated so as to ensure that all the heat from the heater is dissipated through the heatsink only. Six numbers of J-type thermocouples are suitably placed in the base of the heatsink so as to measure the base temperature of the heat sink and a separate thermocouple is placed on the experimental bench to measure the ambient temperature. These thermocouples are connected to the data logger and computer setup (Data Acquisition System). Figure 8 shows the schematic representation of the arrangement for the experimentation.

The photograph of experimental setup is shown in Fig. 9. The experiment was conducted by varying the heat loads from $10-80 \mathrm{~W}$ in the interval of each $10 \mathrm{~W}$. The temperatures at various base locations of heat sink are

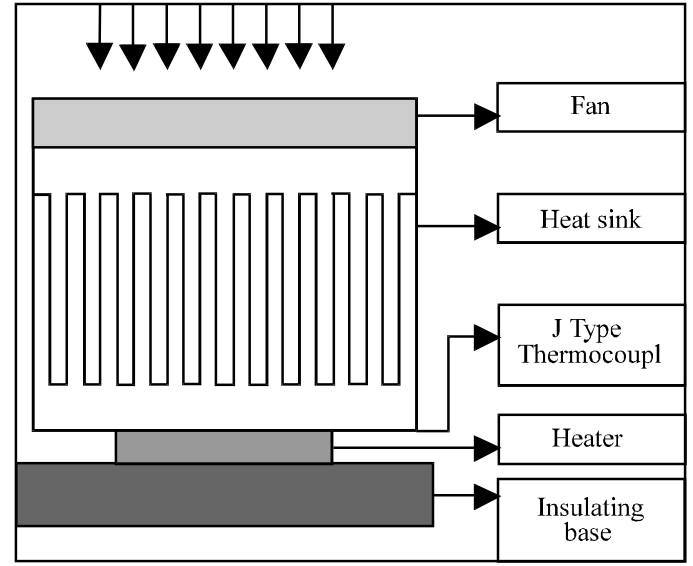

Fig. 8: Schematic diagram for the experimental arrangement

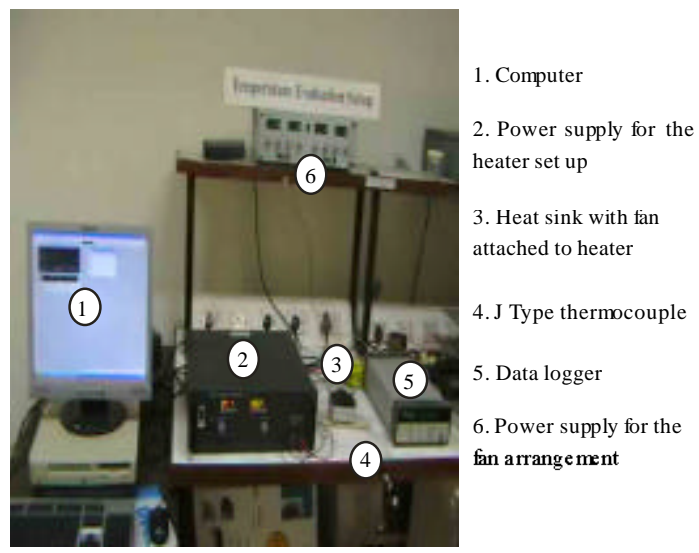

Fig. 9: Experimental setup for measuring the base temperature of the heatsink

measured and recorded using data logger and computer. Also the values of voltage and current of the heaters power supply are noted to find the total power applied to the heater. Anemometer is used to find the fan velocity at $12 \mathrm{~V}$ and it is found to be $5.5 \mathrm{~m} \mathrm{sec}^{-1}$.

From the average values of base temperature, the experimental value of thermal resistance of a heat sink is found as $0.2447^{\circ} \mathrm{K} \mathrm{W}^{-1}$ and the deviation with simulation results are very minimal (3.22\%). Hence, simulation model is found to be in good agreement with the experimental model.

Taguchi design of experiments: The heat sink geometry design factors like Length of the heat sink (L), Width of the heat sink (W), height of the fin (a), base height of the heat sink (b), Number of fins (N), Fin thickness (d) are chosen as the design parameters ( 6 factors with 3 levels (low, medium, high)) for the generation of orthogonal 
array. The Minimum Number of Experimental combinations (MNE) for conducting simulations are given by $\mathrm{MNE}=\mathrm{k}^{\mathrm{n}}$, Where $\mathrm{k}$ is the number of levels and $\mathrm{n}$ is the number of factors. Full factorial method gives $729\left(3^{6}\right)$ experiments. Since, it is difficult and tedious to do all the experiments/simulations, Taguchi Orthogonal array method is used instead of full factorial method to reduce the number of experiments/simulations which gives similar results as in full factorial method. Hence we use the L27 Orthogonal array with the 6 factors at 3 levels generated using Minitab software and it is given in Table 3.

Since it is not feasible to fabricate all the heat sink geometry combinations for the experimental investigations, we have opted for the HFSS simulations for the combinations generated using L27 Taguchi method. HFSS simulations are set to run for $3 \mathrm{GHz}$ for all the 27 combinations generated by design of experiments. The total radiations from the heat sink are obtained at a

\begin{tabular}{|c|c|c|c|}
\hline Design parameters & $\begin{array}{l}\text { Level } 1 \\
\text { (low) }\end{array}$ & $\begin{array}{l}\text { Level } 2 \\
\text { (medium) }\end{array}$ & $\begin{array}{l}\text { Level } 3 \\
\text { (high) } \\
\end{array}$ \\
\hline Length of the heat sink (L) $\mathrm{mm}$ & 70 & 80 & 90 \\
\hline Width of the heat sink (W) $\mathrm{mm}$ & 70 & 80 & 90 \\
\hline No of fins $(\mathrm{N})$ & 10 & 20 & 30 \\
\hline Fin height (a) mm & 10 & 20 & 30 \\
\hline Base height (b) mm & 4 & 6 & 8 \\
\hline Fin thickness (d) mm & 0.8 & 1 & 1.2 \\
\hline
\end{tabular}

distance of $3 \mathrm{~m}$ from the heat sink by simulation and specified in the Table 4. Similarly, CFD simulations are set to run for the 27 combinations at a heat load of $80 \mathrm{~W}$ to find the thermal resistance. The values of emitted radiation and thermal resistance are given in Table 4.

Prediction of emitted radiation and thermal resisitance of heat sink using linear regression analysis: Regression analysis is the statistical technique that identifies the relationship between more than two quantitative variables. A dependent variable can be predicted from these independent or explanatory variables. Thus, the general purpose of multiple regressions is to find the relationships between several independent variables and a dependent variable. This technique is useful when the form of the equation that represents the relationship between the variables is not known. In a linear regression analysis, the relationship between an independent variable $\mathrm{X}$ and a dependent variable $\mathrm{Y}$ is linear, thus $\mathrm{Y}=\mathrm{a}+\mathrm{bX}$ (where $\mathrm{a}$ and $\mathrm{b}$ are constants). Here a linear equation of the form, $Y=a_{0}+$ $\mathrm{a}_{1} \mathrm{X}_{1}+\mathrm{a}_{2} \mathrm{X}_{2}+\ldots+\mathrm{a}_{\mathrm{n}} \mathrm{X}_{\mathrm{n}}$ is assumed to relate the independent variables, $\left(\mathrm{X}_{i}\right)$ and the dependent variable (Y), here $\mathrm{a}_{\mathrm{i}}$ 's are constants. The model constants $\mathrm{a}_{\mathrm{i}}$ 's are determined from the available data using standard regression analysis technique.

Table 4: Taguchi L27 heat sink combinations with corresponding response

\begin{tabular}{|c|c|c|c|c|c|c|c|c|}
\hline \multirow{3}{*}{$\begin{array}{l}\mathrm{L} 27 \\
\text { experiments }\end{array}$} & \multirow[b]{3}{*}{ Length } & \multicolumn{5}{|c|}{ Heat sink design factors } & \multirow{2}{*}{\multicolumn{2}{|c|}{ Multiple responses studied }} \\
\hline & & & & & & & & \\
\hline & & Width & height & height & thickness & of fins & $\mathrm{R}_{\sin }{ }^{0} \mathrm{~K} \mathrm{~W}^{-1}$ & Radiation (db) \\
\hline 1 & 70 & 70 & 10 & 4 & 0.8 & 10 & 0.881965 & 11.303 \\
\hline 2 & 70 & 70 & 10 & 4 & 1.0 & 20 & 0.432559 & 11.379 \\
\hline 3 & 70 & 70 & 10 & 4 & 1.2 & 30 & 0.293341 & 12.930 \\
\hline 4 & 70 & 80 & 20 & 6 & 0.8 & 10 & 0.702373 & 12.144 \\
\hline 5 & 70 & 80 & 20 & 6 & 1.0 & 20 & 0.323024 & 11.940 \\
\hline 6 & 70 & 80 & 20 & 6 & 1.2 & 30 & 0.212195 & 13.371 \\
\hline 7 & 70 & 90 & 30 & 8 & 0.8 & 10 & 0.645489 & 14.852 \\
\hline 8 & 70 & 90 & 30 & 8 & 1.0 & 20 & 0.299137 & 15.364 \\
\hline 9 & 70 & 90 & 30 & 8 & 1.2 & 30 & 0.191255 & 15.702 \\
\hline 10 & 80 & 70 & 20 & 8 & 0.8 & 20 & 0.269675 & 14.207 \\
\hline 11 & 80 & 70 & 20 & 8 & 1.0 & 30 & 0.179465 & 14.525 \\
\hline 12 & 80 & 70 & 20 & 8 & 1.2 & 10 & 0.551366 & 14.430 \\
\hline 13 & 80 & 80 & 30 & 4 & 0.8 & 20 & 0.271091 & 12.626 \\
\hline 14 & 80 & 80 & 30 & 4 & 1.0 & 30 & 0.177363 & 13.327 \\
\hline 15 & 80 & 80 & 30 & 4 & 1.2 & 10 & 0.528742 & 12.122 \\
\hline 16 & 80 & 90 & 10 & 6 & 0.8 & 20 & 0.448907 & 15.290 \\
\hline 17 & 80 & 90 & 10 & 6 & 1.0 & 30 & 0.299522 & 15.650 \\
\hline 18 & 80 & 90 & 10 & 6 & 1.2 & 10 & 0.818506 & 15.020 \\
\hline 19 & 90 & 70 & 30 & 6 & 0.8 & 30 & 0.163617 & 16.716 \\
\hline 20 & 90 & 70 & 30 & 6 & 1.0 & 10 & 0.455578 & 15.738 \\
\hline 21 & 90 & 70 & 30 & 6 & 1.2 & 20 & 0.202934 & 16.406 \\
\hline 22 & 90 & 80 & 10 & 8 & 0.8 & 30 & 0.241451 & 15.960 \\
\hline 23 & 90 & 80 & 10 & 8 & 1.0 & 10 & 0.650075 & 15.020 \\
\hline 24 & 90 & 80 & 10 & 8 & 1.2 & 20 & 0.650092 & 15.730 \\
\hline 25 & 90 & 90 & 20 & 4 & 0.8 & 30 & 0.212911 & 15.746 \\
\hline 26 & 90 & 90 & 20 & 4 & 1.0 & 10 & 0.591928 & 15.060 \\
\hline 27 & 90 & 90 & 20 & 4 & 1.2 & 20 & 0.287743 & 15.470 \\
\hline
\end{tabular}


Hence we propose a new strategic approach for the prediction of radiations emitted from a heat sink at a particular frequency using multiple linear regression analysis. This approach incorporates Taguchi experimental design with regression analysis. Taguchi experimental design is used to generate the input variables into the simulation program, which has been discussed in the previous section. In the present problem, the heat sink design variables like length (L), width (W), fin height (a), base height (b), number of fins $(\mathrm{N})$ and fin thickness (d) are considered as independent variables and the radiations emitted is the dependent variable. These input variables ( $L, W, a, b, N, d)$ are given as inputs to the linear regression analysis and the regression coefficient constants of the above variables are assumed to be $a_{1}, a_{2}$, $\mathrm{a}_{3}, \mathrm{a}_{4}, \mathrm{a}_{5}$ and $\mathrm{a}_{6}$, respectively. The dependent variable, $\mathrm{Y}$ (emitted radiation and thermal resistance) is given by:

$$
\mathrm{Y}=\mathrm{a}_{0}+\mathrm{a}_{1} \mathrm{~L}+\mathrm{a}_{2} \mathrm{~W}+\mathrm{a}_{3} \mathrm{a}+\mathrm{a}_{4} \mathrm{~b}+\mathrm{a}_{5} \mathrm{~d}+\mathrm{a}_{6} \mathrm{~N}
$$

The linear regression analysis is carried out using Minitab software and the values of coefficients of the independent variables are given in Table 5. Also, from the regression coefficients obtained, the regression equation for predicting radiations emitted is given in Eq. 3 .

$$
\begin{aligned}
\text { Radiation }\left(\mathrm{dBmVm}^{-1}\right) & =-5.17+0.127 \text { Length }+0.0584 \\
& \text { Width }+0.0254 \text { Fin height }+0.440 \\
& \text { BaseHeight }+0.649 \text { Fin } \\
& \text { thicknesses }+0.0458 \text { Number of fins }
\end{aligned}
$$

Table 5: Results of linear regression analysis for predicting radiations emitted from a heat sink

\begin{tabular}{lllll}
\hline & $\begin{array}{l}\text { Coefficients } \\
\text { value }\end{array}$ & $\begin{array}{l}\text { SE } \\
\text { coefficient }\end{array}$ & $\mathrm{T}$ & $\mathrm{p}$ \\
\hline Constant, $\mathrm{a}_{0}$ & -5.175 & 2.482 & -2.09 & 0.050 \\
Length, $\mathrm{a}_{1}$ & 0.12701 & 0.01900 & 6.69 & 0.000 \\
Width, $\mathrm{a}_{2}$ & 0.05844 & 0.01900 & 3.08 & 0.006 \\
Fin height, $\mathrm{a}_{3}$ & 0.02539 & 0.01900 & 1.34 & 0.196 \\
Base height, $\mathrm{a}_{4}$ & 0.43964 & 0.09498 & 4.63 & 0.000 \\
Fin thickness, $\mathrm{a}_{5}$ & 0.6492 & 0.9498 & 0.68 & 0.502 \\
Number of fins, $\mathrm{a}_{6}$ & 0.04577 & 0.01900 & 2.41 & 0.026 \\
\hline $\mathrm{S}=0.805894 ; \mathrm{R}-\mathrm{Sq}=80.7 \% ; \mathrm{R}-\mathrm{Sq}$ (Adj.) $=74.9 \%$ & &
\end{tabular}

Table 6: Results of linear regression analysis for predicting thermal

\begin{tabular}{lllll}
\multicolumn{5}{c}{ resistance of a heat sink } \\
\hline Predictors & Coefficients value & SE coefficient & \multicolumn{1}{c}{$\mathrm{T}$} & $\mathrm{p}$ \\
\hline Constant, $\mathrm{a}_{0}$ & 1.1322 & 0.2723 & 4.16 & 0.000 \\
Length, $\mathrm{a}_{1}$ & -0.002917 & 0.002084 & -1.40 & 0.177 \\
Width, $\mathrm{a}_{2}$ & 0.002027 & 0.002084 & 0.97 & 0.342 \\
Fin height, $\mathrm{a}_{3}$ & -0.009896 & 0.002084 & -4.75 & 0.000 \\
Base height, $\mathrm{a}_{4}$ & 0.00001 & 0.01042 & 0.00 & 0.999 \\
Fin thickness, $\mathrm{a}_{5}$ & -0.0281 & 0.1042 & -0.27 & 0.790 \\
Number of fins, $\mathrm{a}_{6}$ & -0.021416 & 0.002084 & -10.27 & 0.000 \\
\hline
\end{tabular}

$\mathrm{S}=0.0884334 ; \mathrm{R}-\mathrm{Sq}=86.8 \% ; \mathrm{R}-\mathrm{Sq}($ Adj. $)=82.8 \%$
Similarly, the values of coefficients of the independent variables for predicting the thermal resistance are given in Table 6 and the corresponding regression equation is given in Eq. 4.

$$
\begin{aligned}
\mathrm{R}_{\text {sin }}= & 1.13-0.00292 \text { Length }+0.00203 \text { Width }-0.00990 \\
& \text { Fin height }+0.0000 \text { Base Height }-0.028 \\
& \text { Fin thickness }-0.0214 \text { Number of fins }
\end{aligned}
$$

\section{RESULTS AND DISCUSSION}

The L27 combinations generated using Taguchi design of experiments were used to test the regression model developed and the comparison graphs for the prediction of emitted radiations and thermal resistance as against the simulation results are shown in Fig. 10 and 11, respectively. It is observed that the residual error was very minimal in the range between -1.5 to +1.5 as shown in Fig. 12. Therefore we infer that the predicted model will serve as a good alternative tool for both the simulation

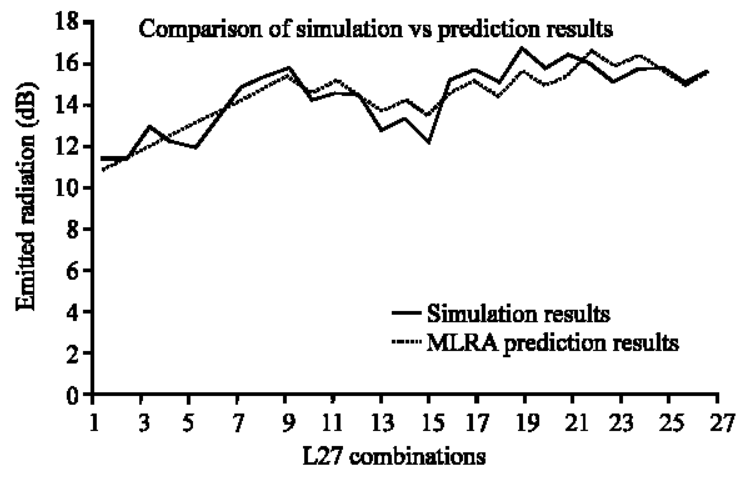

Fig. 10: Comparison of simulation results vs. MLRA prediction of radiations emitted from the heat sink

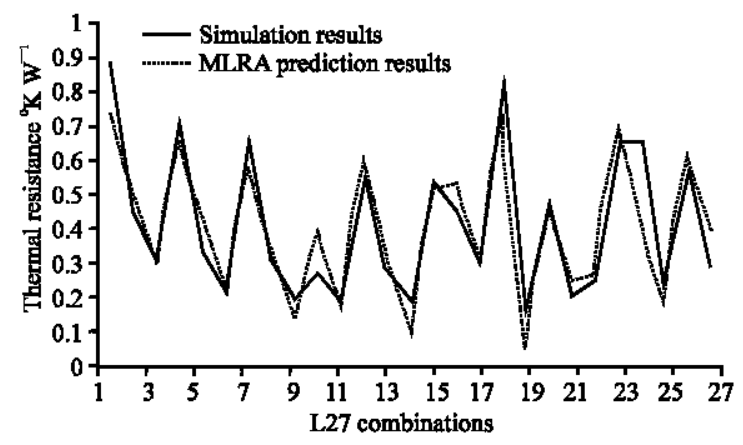

Fig. 11: Comparison of simulation results vs. MLRA prediction of thermal resistance 


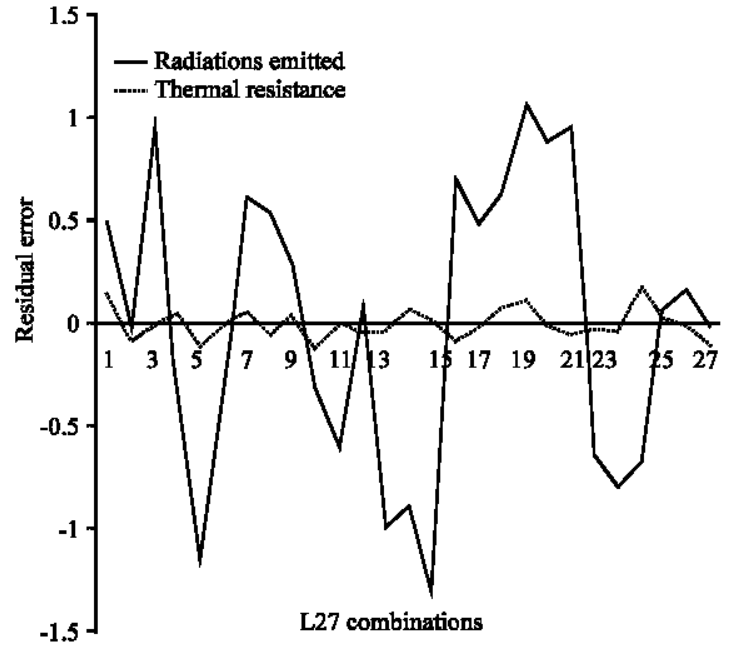

Fig. 12: Residual graph for the responses

software's in determining the responses, where the multiple linear regression model saves enormous amount of time and cost of simulation software's.

\section{CONCLUSION}

Taguchi based multiple linear regression models were developed for the flat plate heat sink for obtaining the responses like emitted radiation and thermal resistance. The factors considered for the L27 orthogonal array construction are the length, width, height of the fin, base height, number of fins and fin thickness of the heat sink. The simulation runs were conducted to find the two responses, emitted radiations and thermal resistance using Ansoft HFSS and Flotherm software, respectively. The Meta model developed using multiple linear regression models are used to calculate the values of responses and it replaces the simulation software's by saving the time and cost of the software.

\section{NOMENCLATURE}

$\lambda=$ Wavelength $(\mathrm{m})$

$\mathrm{a}=$ Fin height $(\mathrm{mm})$

$\mathrm{b}=$ Base thickness of the heat sink $(\mathrm{mm})$

$\mathrm{d}=$ Fin thickness $(\mathrm{mm})$

$\mathrm{f}=$ Frequency $(\mathrm{Hz})$

$\mathrm{L}=$ Heat sink length $(\mathrm{mm})$

$\mathrm{N}=$ Number of fins

$\mathrm{Q}=$ Heat dissipation $(\mathrm{W})$

$\mathrm{R}_{\text {sin }}=$ Total thermal resistance $\left({ }^{0} \mathrm{~K} \mathrm{~W}^{-1}\right)$

$\mathrm{T}_{\mathrm{a}}=$ Ambient temperature $\left({ }^{0} \mathrm{~K}\right)$

$\mathrm{T}_{\mathrm{b}}=$ Temperature of fin base $\left({ }^{0} \mathrm{~K}\right)$

$\mathrm{W}=$ Heat sink width $(\mathrm{mm})$

\section{REFERENCES}

Archambeault, B., S. Pratapneni, L. Zhang, D.C. Wittwer and J. Chen, 2001. A proposed set of specific standard EMC problems to help engineers evaluate EMC modeling tools. IEEEInt. Symp. Electromagnetic Compatibil., 2: 1335-1340.

Arularasan, R. and R. Velraj, 2008. Modeling and simulation of a parallel plate heat sink using computational fluid dynamics. Int. J. Adv. Manuf. Technol., 10.1007/s00170-008-1867-9

Bar-Cohen, A. and W.M. Rohsenow, 1984. Thermally optimum spacing of vertical natural convection cooled parallel plates. ASME J. Heat Transfer, 106: 116-123.

Bar-Cohen, A., 1992. State-of-the-art and trends in the thermal packaging of electronic equipment. $\mathrm{J}$. Electromagnetic Package, 114: 257-270.

Brench, C.E., 1994. Heat sink radiation as a function of geometry. Proceedings of IEEE Symposium, Electromoagnetic Compatibility, Aug. 22-26, Chicago, IL, pp: 105-109.

Chen, C.T., C.K. Wu and C. Hwang, 2008. Optimal design and control of CPU heat sink processes, components and packaging technologies. IEEE Trans., 31: 184-1 95.

Chou, C.C., N.M. Liu, J.T. Horng and K.T. Chiang, 2009. Designing parameter optimization of a parallel-plain fin heat sink using the grey-based fuzzy algorithm with the orthogonal arrays. Int. J. Thermal Sci., 48: 2271-2279.

Culham, J.R. and Y.S. Muzychka, 2001. Optimization of plate fin heatsinks using entropy generation minimization. Proc. IEEE Intersociety Conf. Thermal Phenomena, 24: 159-165.

Das, S.K. and T. Roy, 1998. An investigation on radiated emissions from heat sink. IEEE Int. Symp. Electromagnetic Compatibility, 2: 784-789.

Georgerian, R. and M.I. Mantrose, 2003. Product safety and the heat sink-Dilemma of minimizing radiated emissions and maximizing thermal cooling. IEEE Int. Symp. Electromagnetic Compatibil., 1: 134-137.

Golkhab, M. and M.T. Bina, 2008. Multilevel converter objectives a critical evaluation and combination of available natural commuted topologies with restructured iron cores. Proceedings of World Congress on Engineering and Computer Science 2008, Oct. 22-24, San Francisco, USA., pp: 428-433.

Khan, W.A., M.M. Yovanovich and J.R. Culham, 2006. Optimization of microchannel heatsinks using entropy generation minimization method. Proceedings of IEEE International Conference on Semiconductor Thermal Measurement and Management Symposium, March 14-16, Dallas, TX, pp: $78-86$. 
Kraus, A.D. and A. Bar-Cohen, 1995. Design and Analysis of Heatsinks. Wiley- Interscience, New York, ISBN: 978-0471017554.

$\mathrm{Lu}, \mathrm{J}$. and F. Dawson, 2006. EMC computer modeling techniques for CPU heat sink simulation. IEEE Trans. Magn., 42: 3171-3173.

$\mathrm{Lu}, \mathrm{J}$. and X. Duan, 2007. Comparative analysis of intel pentium 4 and IEEE/EMC TC-9/ACEM CPU heat sinks. Proceedings of the IEEE International Symposium on Electromagnetic Compatibility, July 9-13, Honolulu, HI, pp: 1-6.

Parry, J., 2000. Multiphysics modeling for electronics design. Thermal Thermomechanical Phenomena Electronics Syst., 2: 86-93.

Rao, T., 2001. Fundamentals of Microelectronic Packaging. 1st Edn., McGraw-Hill, USA., ISBN: 9780071371698.
Shah, A., B. Sammakia and H. Srihari, 2002. A numerical study of the thermal performance of an impingement heat sink fin shape optimization. Proceedings of the 8th Intersociety Conference on Thermal and Thermomechanical Phenomena in Electronic Systems, May 30-June 1, ITHERM, pp: 298-306.

Visser, J.A., D.J. de Kock and F.D. Conradie, 2000. Minimisation of heatsink mass using mathematical optimization. IEEE-Semiconductor Thermal Measurement and Management Symposium, March 21-23, San Jose, CA, pp: 252-259.

Yu, J., P. Sochoux, A. Bhobe and F. Centola, 2008. Heatsink design flow for EMC. Design Con 2008, IEC Publications, pp: 1 -27. http://www.cst.com/Content/ Documents/Articles/article416/HeatsinkDesignFlo w_CST_May212008.pdf. 